\title{
Application of Capillary Electrophoretic On-Line Sequential Concentration Based on Micelle to Solvent Stacking
}

\author{
Shan Sun ${ }^{1,2,3,4}$, Yuanqi Lu*, Zhe Yuan 1,2,3,4, Qingqiang Yao \\ ${ }^{1}$ School of Medicine and Life Sciences, University of Jinan-Shandong Academy of Medical Sciences, Jinan, China \\ ${ }^{2}$ Institute of Materia Medica, Shandong Academy of Medical Sciences, Jinan, China \\ ${ }^{3}$ Key Laboratory for Rare \& Uncommon Diseases of Shandong Province, Jinan, China \\ ${ }^{4}$ Analysis and Testing Centre, Dezhou University, Dezhou, China \\ Email: *luyuanqi2002@hotmail.com
}

How to cite this paper: Sun, S., Lu, Y.Q. Yuan, Z. and Yao, Q.Q. (2018) Application of Capillary Electrophoretic On-Line Sequential Concentration Based on Micelle to Solvent Stacking. American Journal of Analytical Chemistry, 9, 52-63.

https://doi.org/10.4236/ajac.2018.91005

Received: September 22, 2017

Accepted: January 15, 2018

Published: January 18, 2018

Copyright (c) 2018 by authors and Scientific Research Publishing Inc. This work is licensed under the Creative Commons Attribution International License (CC BY 4.0).

http://creativecommons.org/licenses/by/4.0/

\begin{abstract}
To take advantage of micelle to solvent stacking (MSS) to achieve more sensitivity enhancement with enough selectivity, the application of capillary electrophoretic on-line sequential concentration based on the MSS was reviewed. MSS has been coupled to sweeping FASS, FASI and normal EKI. Furthermore, multiple stacking by coupling MSS with more than one stacking method has also been reported. It is more sensitive and selective than solely used of one or two stacking methods and is very suitable for complex and trace sample analysis.
\end{abstract}

\section{Keywords}

Capillary Electrophoresis (CE), On-Line Sequential Concentration, Micelle to Solvent Stacking (MSS)

\section{Introduction}

Due to its small volume and the narrow optical path, CE suffers from poor concentration sensitivity, especially when on-line UV detection is utilized [1] [2]. To enhance the detection ability of $\mathrm{CE}$, a number of on-line concentration techniques have been developed. These techniques are based on the changes in the analyte migration velocity at the boundary between sample zone and the background electrolyte [3] [4]. Of these techniques, stacking based on association between the analytes and the surfactants are very useful. MSS is a kind of technique based on this principle, in which the sample is prepared in a micellar solu- 
tion without an organic solvent or its aqueous solution. Because the organic solvent in the background electrolyte (BGE) affects the micellar interaction with the analytes, the effective electrophoretic directions of the analytes will reverse at the micellar to solvent stacking boundary (MSSB), therefore causing the analytes focusing [5] [6]. It was first introduced by Quirino and co-workers for the stacking of small organic cations [7] and has already been widely used to analyze organic cations and anions in waste water [8], traditional Chinese medicine [9] and biological fluids [10] [11] [12] analysis. Although sensitivity enhancements of 40 - 1000-fold and detection limits of $0.1-0.001 \mathrm{mg} / \mathrm{L}$ have been achieved with MSS, its selectivity and sensitivity still can't meet the requirements of real sample analysis. To acquire additional detection ability enhancements, sequential capillary electrophoretic stacking by coupling MSS with other CE on-line concentration techniques has been developed. These sequential on-line techniques include coupling MSS with sweeping (sweeping-MSS) [13] [14] [15], field amplified sample stacking (FASS-MSS) [16] [17], field amplified sample injection (FASI-MSS) [18] [19] [20] [21] [22], MSS via normal EKI sample injections with the assistance of micelles [23] [24] [25] as well as field amplified sample injection and sweeping (FASI-sweeping-MSS) [26] [27]. Compared to single used of MSS, the sequential stacking techniques can enhance the sensitivity $2-10$ more times and these methods can be more selective to specific analytes. The developments of these sequential techniques have been included in the review of Yang et al. [28]. But it is not comprehensive and the works of these techniques after 2013 were not included. In this paper, the application of sequential on-line concentration methods based MSS was reviewed.

\section{Sweeping-MSS}

Recently, a novel two-step stacking strategy of sweeping-MSS was introduced. In such strategy, the sample matrix was free of the micelles and a plug of anionic (cationic analytes) or cationic (anionic analytes) micellar solution was injected before sample solution in order to perform sweeping [13]. After the sweeping step, the enriched analyte bound to the micelles were transported to the MSSB where they experienced an organic solvent in the BGE. The solvent reduced the interaction between the micelles and the analytes. The direction of the effective electrophoretic mobility reverses at the MSSB. This caused the focusing of the analytes at the MSSB. Compared to single MSS stacking, sweeping-MSS can enhance the sensitivity of analytes 2 - 5 times further. Sweeping-MSS was first introduced by Quirino to determine four $\beta$-blockers and two tricyclic antidepressant drugs with capillary zone electrophoresis (CZE)separation [13] and now they have been widely used in organic cations [13] [14] [15] and anions [29] [30] analysis. Yang et al. developed a sweeping-MSS technique in CZE and applied this method to determine quinolizidine alkaloids in traditional Chinese medicines. Under the optimum conditions, the sensitivity enhancement factors (SEFs) obtained by the developed method for the analytes were in the $42-52$ 
fold range [14]. Yang et al. proposed a sweeping-MSS method for fast stacking of nitroimidazoles in CZE. With this method, dimetridazole, metronidazole and secnidazole can be determined in $9 \mathrm{~min}$. The detection limits and sensitivity enhancements are in the $2.3-3.0 \mathrm{ng} / \mathrm{mL}$ and 12 - 38-fold range, respectively [15]. Yang et al. developed a sweeping-MSS on-line concentration method in CZE to determine strychine and brucine in traditional Chinese herbal medicines. The detection limits for the two analytes were $0.01 \mu \mathrm{g} / \mathrm{mL}$. Compared with typical CZE, 38 - 51-fold sensitivity enhancement were achieved [31]. Quirino et al. have developed a sweeping-MSS method using cationic cetyltrimethylammonium micelles in CZE to determine hypolipidemic drugs, herbicides and nonsteroidal anti-inflammatory drugs. In their work, the direction of electroosmotic flow (EOF) was the same as the anions which were achieved by positive dynamic coating of a fused silica capillary with hexadimethrine bromide. The sensitivity enhancements based on peak height were in the 17 - 33-fold range. The limits of detections (LODs) were from $0.05-0.55 \mu \mathrm{g} / \mathrm{mL}$ range [29]. Wang et al. developed a long-chain ionic liquid (LCIL)-based sweeping-MSS method in CZE for anionic compounds analysis. In their work, N-Cetyl-N-methylpyrrolidinium bromide $\left(\mathrm{C}_{16} \mathrm{MPYBr}\right)$ was used as a novel cationic surfactant. The capillary column was conditioned with poly (1-vinyl-3-butylimidazolium) bromide, a kind of polymeric ionic liquid, to obtain the anodic EOF. Under the optimized conditions, the peak areas of benzoic acid and 2-nitrophenol were increased 34 and 25 times and the peak height of 4-chlorophenol was increased 60 times [30].

\section{Micelle to Solvent Stacking via Sample Injection under Field Enhanced Conditions}

When the conductivity of the sample zone is much lower than the BGE zone thus electric field of the sample zone is much higher than that of the BGE when the voltage is applied. As a result, the analytes sped down and accumulated at the boundary between the sample zone and the BGE. When the sample was introduced with pressure, it is called field amplified sample stacking (FASS). When the sample was introduced electrokinetically, it is called field amplified sample injection (FASI) [32]. MSS relies on the transport of the micelle bound charged analyte and the reversal of the analytes' effective electrophoretic mobility at the MSS boundary between the micellar zone and the adjacent zone [7]. When coupling MSS with FASS, the sample was solved in a low conductivity micellar solution (S). A solution with low conductivity containing large proportion of organic solvent was used as trapping solution (TS). After the capillary was preconditioned with the running buffer, $\mathrm{S}$ and TS were sequentially introduced. When the positive separation voltage was applied, the analytes loaded by the negatively charged sodium dodecylsulfate (SDS) micelles will continuously fall down into the organic solvent in the TS, in which the concentration of SDS is below the critical micelle concentration (CMC), consequently releasing and accumulating the transported molecules. The analytes are released into the organic 
solvent zone with a low conductivity in which a high electric field is provided, resulting in a high analyte migration velocity. When the ionized analytes arrive at the boundary between the organic solvent zone and BGE zone, the electric field strength suddenly decreases, and the migration velocities of the analytes become slower resulting in the gathering of the analytes near the boundary [16]. As the MSS step is before the FASS step, this sequential method is called micelle to solvent stacking-field amplified sampling stacking (MSS-FASS). But when the conductivity of TS is higher than the sample matrix and the EOF is negligible, the organic solvent in the TS solution can't react with the micellar first. On the contrary, the SDS micelles in the sample zone rapidly moved into TS under high electric field intensity. Due to the electric filed strength of TS is lower than that of sample solution, the analytes slowed down quickly and accumulated at the border between sample zone and the TS zone, which is a FASS process. Thereafter, once the mixed micelles have access into the organic solvent zone, the micelles would collapse and release the analytes, in which a MSS process occurred. As the FASS step is before the MSS step, this sequential method is called micelle to solvent stacking-field amplified sampling stacking (FASS-MSS). Liu et al. have poposed a MSS-FASS method in CZE to determine trimethoprim and sulfamethoxazole in animal-originated foodstuffs. LODs of $7.7-8.5 \mathrm{ng} / \mathrm{mL}$ were achieved which were 301 and 329 times better compared to a typical injection, respectively [16]. Wan et al. [17] have developed FASS-MSS method with the aid of $\beta$-cyelodextrin $(\beta$-CD) to determine the contents of atenolol and metoprolol in human urine by CE. Improvement in the sensitivity for analytes is achieved up to 200-fold compared with conventional CE method. The LODs can be reached 3.3 and $3.7 \mathrm{ng} / \mathrm{mL}$, respectively.

In FASI-MSS, the conductivity of the sample solution is much lower than that of the BGE and the micellar solutions. There are big amounts of organic solvents in the sample matrix. After preconditioning the capillary with the BGE, a micelle solution (MS) plug was introduced with hydrodynamic injection. The sample solution was introduced with hydrodynamic injection for a short time to enhance the electric field strength at the injection point during FASI (Sometimes this step can be omitted, as sample eluent introduced via the low EOF during FASI can also function for this purpose). Then the sample was electrokinetically injected for a long time. The analytes electrophoretically migrate to the positive (anions) or negative (cations) electrode while the micelles travel toward the opposite end. The analytes become trapped in the positively (anions) or negatively (cations) charged micelles, and the micelle-bound analytes travel toward the negative (anionic analytes) or positive (cationic analytes) electrode. The organic solvent present in the sample matrix decreases the affinity of the analytes to the micelles, leading to the release of the analytes from the micelles. Analyte focusing occurs at the MSSB and then the analytes are separated by CZE [18] [19] [21] or nonaqueous capillary electrohporesis [20]. As shown in Table 1, compared to Sweeping-MSS, MSS-FASS and FASS-MSS, more analytes can be 
Table 1. Comparison between sweeping-MSS and coupling field enhancement with MSS.

\begin{tabular}{|c|c|c|c|c|}
\hline $\begin{array}{l}\text { Stacking } \\
\text { techniques }\end{array}$ & $\begin{array}{l}\text { Stacking } \\
\text { mechanism }\end{array}$ & Sample diluent & Sample clean-up & SEF \\
\hline Sweeping-MSS & $\begin{array}{l}\text { Association between } \\
\text { analytes and micelle, } \\
\text { collapse initiated by } \\
\text { organic solvent in BGE }\end{array}$ & $\begin{array}{c}\text { Same kind of } \\
\text { buffer as BGE } \\
\text { without micelle }\end{array}$ & $\begin{array}{c}\text { Need sample clean-up } \\
\text { process }\end{array}$ & $\begin{array}{c}12-60 \\
{[14][15][29]} \\
{[30][31]}\end{array}$ \\
\hline MSS-FASS & $\begin{array}{l}\text { Micelle collapse initiated by } \\
\text { organic solvent in TS, high } \\
\text { electric field created by } \\
\text { organic solvent in the TS }\end{array}$ & Micelle solution & $\begin{array}{c}\text { Need sample } \\
\text { clean-up process }\end{array}$ & $301-329$ [16] \\
\hline FASS-MSS & $\begin{array}{c}\text { The conductivity difference } \\
\text { between low conductivity } \\
\text { sample and the TS, micelle } \\
\text { collapse initiated by } \\
\text { organic solvent in TS }\end{array}$ & Micelle solution & $\begin{array}{c}\text { Need sample clean-up } \\
\text { process }\end{array}$ & $200[17]$ \\
\hline FASI-MSS & $\begin{array}{l}\text { High electric field created } \\
\text { by organic solvent in the } \\
\text { sample solution, micelle } \\
\text { collapse initiated by } \\
\text { organic solvent in sample } \\
\text { diluent }\end{array}$ & $\begin{array}{c}\text { Low conductivity } \\
\text { sample diluent } \\
\text { containing large } \\
\text { amount of } \\
\text { organic solvent }\end{array}$ & $\begin{array}{l}\text { Need sample clean-up } \\
\text { process and the } \\
\text { sample amount is } \\
\text { vulnerable to sample } \\
\text { ionic strength changes }\end{array}$ & $\begin{array}{c}200-2534 \\
{[18][19][20]} \\
{[21][22]}\end{array}$ \\
\hline
\end{tabular}

introduced in FASI-MSS, which can permit much bigger sensitivity enhancements. Besides, it is the organic solvent in the sample matrix rather than that in the BGE or TS that initiated the MSS process in FASI-MSS. Although these stacking techniques all need sample clean-up, the stacking efficiency is more vulnerable to ionic strength changes in the sample matrix for its low conductivity requirement. Rabanes et al. have developed a FASI-MSS method in CZE to determine cationic drugs in urine. Using a sample diluent with one-tenth the conductivity of the background solution, the strategy afforded as high as 2479fold improvements in peak height and LODs of as low as $1.1-1.8 \mathrm{ng} / \mathrm{mL}$ [19]. Tubaon et al. developed a FASI-MSS method in CZE to determine anionic sulfonamides in river water samples. Cationic cetyltrimethylammonium bromide (CTAB) was used as the surfactant. Compared to typical hydrostatic injection, SEFs of 397 - 1024 have been achieved. Limits of quantitation were in the $0.01-0.3 \mu \mathrm{g} / \mathrm{mL}$ range [18]. Thang et al. has developed a FASI-MSS method in nonaqueous capillary electrophoresis to determine anticancer drugs in major metablites. The proposed method allowed a $214-625$-fold SEF which is 2 - 5 times better than with FASI only [20]. Mohd Azmi et al. [21] have developed and validated a FASI-MSS method to determine paraquat and bromhexine in river water. The sensitivity was enhanced 1000 -fold in comparison to normal CZE. Chong et al. [22] developed a FASI-MSS method in the microchip electrophoresis (MCE) coupled with on-chip contactless conductivity detection $\left(C^{4} \mathrm{D}\right)$ system to determine vancomycin in human plasma. A SEF of up to 217-fold was achieved and the LODs of the method for vancomycin was 1.2 
$\mu \mathrm{g} / \mathrm{mL}$.

\section{Micelle to Solvent Stacking via Normal Electrokinetic Injection}

If there is no apparent difference in conductivity between the sample zone and the BGE, the samples can be introduced with the aid of micelles, during which the effects of EOF can be attenuated by introducing acidic buffer solution [23] [24] or with the assistance of pressure during EKI [25]. Dong et al. combined MSS with large amount sample electrokinetic stacking injection (LASEKSI) in CZE for the analysis of cationic molecules. In this developed MSS-LASEKSI method, after a large amount of sample solution was introduced from the outlet hydrodynamically, co-solvent buffer was injected with pressure from the inlet. And then sample stacking was performed by applying a $10 \mathrm{kV}$ voltage in the normal polarity through the acidic buffer solution ( $\mathrm{pH} 3.0$ ) vial and the sample vial for a period of time, during which the integral EOF was attenuated, and when the velocity of EOF and the micelles are equal, a equilibrium state was formed and can be maintained for a long time, leading to the continuous stacking of the analytes on the basis of MSS. Therefore, an extremely large amount sample was permitted to be injected into the capillary which allowed as high as $6.3 \times 10^{3}$-fold sensitivity enhancement [23]. The developed method has been applied to determine berberine and theophylline in urine samples with recoveries in the range of $98 \%-101 \%$ and $95 \%-112 \%$, respetively. Wuethrich and Quirino proposed the unusual stacking of cationic analytes via EKI of SDS micelles into a fused silica capillary filled with acidic BGE with 40\% - 50\% acetonitrile. Two peaks were observed from an analyte which suggested the concentration of analytes into two stacking zones. The zones were identified as the SDS micelles (micelles zone) and organic solvent-rich stacking zone (solvent rich zone) where the micelles zone was closer to the inlet end of capillary. The concentrated analytes in the micelles zone were from the concentrated analytes that electrophoretically migrated into the micelles zone from the solvent-rich zone during EKI. The analytes in the micelles zone were then re-stacked by MSS and formed the second sharp peak in CZE. This can be prevented by reduction of acetonitrile concentration in the inlet BGE. SEFs of more than 100 times were obtained for diphenhydramine and imipramine, two cationic drugs [24]. Quirino and Aranas have coupled simultaneous electrokinetic and hydro dynamicinjection (SEHI, also named pressure assisted electrokinetic injection) of organic cations with MSS in reversed migration MEKC to determine tricyclic antidepressant and beta blocker drugs in micellar electrokinetic chromatography. As the pressure counteracted the slow moving EOF and maintained the MSSB inside the capillary relatively stable during injection, much more sample ions can be introduced into the capillary which allowed up to 4000 -fold sensitivity enhancement [25]. The method has been applied to determine tricyclic antidepressant and beta blocker drugs in waste water samples with recoveries in the 
$81 \%-87 \%$, range.

\section{MSS Based Multiple Stacking}

Coupling MSS with more than one stacking method, which is called MSS based multiple stacking, can further enhance the sensitivity and selectivity. In Sweeping-MSS, if the sample was injected with FASI, triple stacking by coupling FASI, Sweeping and MSS (FASI-sweeping-MSS) can be achieved. Grochocki et al. have developed a FASI-sweeping-MSS triple stacking method in CZE to determine four penicillins in plasma samples [26]. In their work, the sample was solved in diluted BGE and introduced into the capillary by FASI at negative voltage. Then the $\mathrm{CTAB}$ micelles were introduced at positive voltage and the the positively charged micelles swept the stacked anionic analytes at the sweeping boundary. And then a small plug of $60 \%$ methonal was introduced hydrodynamically, the MSSB was created between the $\mathrm{MeOH}$ and swept analyte zone with micelles. As the negative separation voltage was applied, it resulted in the stacking of the analytes at the MSSB. The SEFs were 146 - 279 and 519 - 954 for conductivity ratio of 10 and 100, respectively. The SEF enhancement factors were $16-32$ and 6 - 10 times better than solely use of FASI. Recoveries of analytes under different concentration levels were in the $72 \%-101 \%$ range. Grochocki et al. [27] have developed a three-step stacking procedure of combining FASI with sweeping and MSS using model cationic drugs. The sensitivity enhancements of this threestep stacking techniques were in the 308 - 891, 2188 - 6463 and 3088 - 6499-fold range, when the conductivity of sample diluent is 10,100 , and $1000 \times$ lower than the BGE, respectively. The method has been applied to plasma sample analysis with recoveries in the $81 \%-124 \%$ range.

\section{Conclusion}

In this paper, the application of capillary electrophoretic on-line sequential concentration techniques based on the MSS has been discussed from four aspects, i.e., sweeping-MSS, field enhancement-MSS, MSS via normal EKI and MSS based multiple stacking. Compared to MSS, sweeping-MSS is more selective, but the sensitivity enhancements are often below one hundred, possibly due to limited sample amount. As much more analytes can be introduced into the capillary, combination of field enhancement with MSS can obtain more sensitivity enhancement and SEF as high as more than one 2000 has been achieved. When coupling MSS with normal EKI, if the EOF was modulated by pressure or acidic buffer, very large amount of analytes can be injected with the aid of micelle and as high as more than three magnitude of sensitivity enhancements can be achieved. MSS based multiple stacking is much more selective and sensitive and can be used to determine trace analytes in complex sample matrix. As shown in Table 2, the application of MSS based sequential stacking techniques has been limited to traditional Chinese medicine, plasma, water and urine sample analysis, which may be due to the limited sample clean-up techniques. 
Table 2. Application of MSS based sequential CE stacking techniques.

\begin{tabular}{|c|c|c|c|c|c|}
\hline Analyte & Sample & $\begin{array}{c}\text { LOD } \\
(\mathrm{ng} / \mathrm{mL})\end{array}$ & SEF & Combined technique & Reference \\
\hline $\begin{array}{l}\text { Alprenolol, propranolol, nadolol, } \\
\text { labetalol, nortriptyline, clomipramine }\end{array}$ & & 20 & $20-46$ & Sweeping-MSS-CZE & 13 \\
\hline Sophocarpine, matrine and oxymatrine & $\begin{array}{l}\text { Traditional Chinese } \\
\text { medicines }\end{array}$ & $20-30$ & $42-52$ & Sweeping-MSS-CZE & 14 \\
\hline Dimetridazole, metronidazole, secnidazole & Rabbit plasma & $2.3-3.0$ & $12-38$ & Sweeping-MSS-CZE & 15 \\
\hline $\begin{array}{l}\text { Gemfibrozil, fluvastatin, atorvastatin, } \\
\text { naproxen, diflunisal, ketoprofen, } \\
\text { indomethacin, indoprofen, mecoprop and } \\
\text { fenofrop }\end{array}$ & Waste water & $50-550$ & $17-33$ & Sweeping-MSS-CZE & 29 \\
\hline $\begin{array}{l}\text { Benzoic acid, 2-nitrophenol, } \\
\text { 4-chlorophenol }\end{array}$ & $\begin{array}{l}\text { Tap water and } \\
\text { Yellow river }\end{array}$ & $25-250$ & $25-60$ & Sweeping-MSS-CZE & 30 \\
\hline Strychnine and brucine & $\begin{array}{c}\text { Traditional Chinese } \\
\text { medicines }\end{array}$ & 10 & $38-51$ & Sweeping-MSS-CZE & 31 \\
\hline Trimethoprim, sulfamethoxazole & $\begin{array}{l}\text { Animal-originated } \\
\text { foodstuffs }\end{array}$ & $7.7-8.5$ & $301-329$ & FASS-MSS-CZE & 16 \\
\hline Atenolol, metoprolol & Urine sample & $3.3-3.7$ & 200 & FASS-MSS-CZE & 17 \\
\hline $\begin{array}{l}\text { Sulfamerazine, sulfamethazine, } \\
\text { sulfamethizole }\end{array}$ & River water & $10-30$ & $397-1024$ & FASI-MSS-CZE & 18 \\
\hline $\begin{array}{l}\text { Quetiapine fumarate, droperidol, } \\
\text { risperidone, olanzapine, } \\
\text { chlorpromazine hydrochloride, } \\
\text { aripiprazole }\end{array}$ & Human urine & $1.1-1.8$ & $717-2479$ & FASI-MSS-CZE & 19 \\
\hline Tamoxifen and its metabolites & Human plasma & $0.15-0.70$ & $214-625$ & FASI-MSS-NACE & 20 \\
\hline Paraquat and bromhexine & River water & $30-50$ & $215-2534$ & FASI-MSS-CZE & 21 \\
\hline Vancomycin & Human plasma & 1200 & 83 & FASI-MSS-MCE & 22 \\
\hline Berberine and theophylline & Human urine & $0.3-0.4$ & $6.4 \times 10^{2}-6.3 \times 10^{3}$ & MSS-LASEKSI-CZE & 23 \\
\hline $\begin{array}{l}\text { Imipramine hydrochloride and } \\
\text { diphenhydramine } \\
\text { hydrochloride }\end{array}$ & & 15 & 100 & EKI-MSS-CZE & 24 \\
\hline $\begin{array}{l}\text { Imipramine hydrochloride, clomipramine } \\
\text { hydrochloride, doxepine hydrochloride, } \\
\text { nortriptyline hydrochloride, alprenolol } \\
\text { hydrochloride, labetalol hydrochloride } \\
\text { and propranolol hydrochloride }\end{array}$ & $\begin{array}{l}\text { Wastewater and } \\
\text { urine }\end{array}$ & $0.6-4.2$ & 4000 & SEHI-MSS-MEKC & 25 \\
\hline $\begin{array}{l}\text { Penicillin G, oxacillin, ampicillin, } \\
\text { amoxicillin }\end{array}$ & Plasma & $6.6-13.2$ & $519-954$ & FASI-sweeping-MSS-CZE & 26 \\
\hline $\begin{array}{l}\text { Dibucaine, diphenhydramine, } \\
\text { propranolol, verapamil }\end{array}$ & Plasma & $10-40$ & $3088-6499$ & FASI-sweeping-MSS-CZE & 27 \\
\hline
\end{tabular}

\section{Acknowledgements}

This work was supported by funding from the Science Foundation of Shandong Province (No. ZR2014JL007).

\section{References}

[1] Simpson Jr., S.L., Quirino, J.P. and Terabe, S. (2008) On-Line Sample Preconcentration in Capillary Electrophoresis Fundamentals and Applications. Journal of Chromatography $A, 1184$, 504-541. https://doi.org/10.1016/j.chroma.2007.11.001

[2] Aranas, A.T., Guidote Jr., A.M. and Quirino, J.P. (2009) Sweeping and New On- 
Line Sample Preconcentration Techniques in Capillary Electrophoresis. Analytical and Bioanalytical Chemistry, 394, 175-185. https://doi.org/10.1007/s00216-009-2646-7

[3] Kitagawa, F. and Otsuka, K. (2014) Recent Applications of On-Line Sample Preconcentration Techniques in Capillary Electrophoresis. Journal of Chromatography A, 1335, 43-60. https://doi.org/10.1016/j.chroma.2013.10.066

[4] Chen, Y.L., Lü, W.J., Chen, F.G. and Teng, M. (2012) Review of Recent Developments of On-Line Sample Stacking Techniques and Their Application in Capillary Electrophoresis. Central European Journal of Chemistry, 3, 611-638.

[5] Thang, L.Y., See, H.H. and Quirino, J.P. (2016) Determination of Tamoxifen and Its Metabolites Using Micelle to Solvent Stacking in Nonaqueous Capillary Electrophoresis. Electrophoresis, 37, 1166-1169. https://doi.org/10.1002/elps.201600010

[6] Zhu, H.D., Lü, W.J., Li, H.H., Ma, Y.H., Hu, S.Q., Chen, H.L. and Chen, X.G. (2011) Micelle to Solvent Stacking of Two Alkaloids in Nonaqueous Capillary Electrophoresis. Journal of Chromatography $A, 1218,5867-5871$.

https://doi.org/10.1016/j.chroma.2011.06.106

[7] Quirino, J.P. (2009) Micelle to Solvent Stacking of Organic Cations in Capillary Zone Electrophoresis with Electrospray Ionization Mass Spectrometry. Journal of Chromatography A, 1216, 294-299. https://doi.org/10.1016/j.chroma.2008.11.062

[8] Guidote Jr., A.M. and Quirino, J.P. (2010) On-Line Sample Concentration of Organic Anions in Capillary Zone Electrophoresis by Micelle to Solvent Stacking. Journal of Chromatography A, 1217, 6290-6295. https://doi.org/10.1016/j.chroma.2010.07.077

[9] Liu, L.H., Deng, X.X. and Chen, X.G. (2010) Micelle to Trapping Solution Stacking in Micellar Electrokinetic Chromatography. Journal of Chromatography A, 1217, 175-178. https://doi.org/10.1016/j.chroma.2009.11.038

[10] Zhang, S.H., Ma, R.Y., Ma, X.M., Wang, C. and Wang, Z. (2012) On-Line Sample Concentration and Determination of Cationic Alkaloids in Human Plasma by $\mathrm{Mi}$ celle to Solvent Stacking in Capillary Zone Electrophoresis. Journal of Chromatography B, 906, 41-47. https://doi.org/10.1016/j.jchromb.2012.08.017

[11] Yang, X.M., Liu, S.J., Wang, C. and Wang, Z. (2014) On-Line Micelle to Solvent Stacking in Capillary Electrophoresis for the Preconcentration of Three Antihistamines from Human Plasma. Analytical Methods, 6, 8640-8644. https://doi.org/10.1039/C4AY01218F

[12] Zhu, H.D., Ren, C.L., Hu, S.Q., Zhou, X.-M., Chen, H.-L. and Chen, X.G. (2011) Thousand Fold Concentration of an Alkaloids in Capillary Zone Electrophoresis by Micelle to Solvent Stacking. Journal of Chromatography A, 1218, 733-738. https://doi.org/10.1016/j.chroma.2010.11.060

[13] Quirino, J.P. (2010) Two-Step Stacking in Capillary Zone Electrophoresis Featuring Sweeping and Micelle to Solvent Stacking: I. Organic Cations. Journal of Chromatography A, 1271, 7776-7780. https://doi.org/10.1016/j.chroma.2010.10.020

[14] Yang, X.M., Liu, S.J., Zhang, S.H. and Wang, Z. (2014) On-Line Two-Step Stacking for the Preconcentration and Determination of Quinolizidine Alkaloids by Capillary Electrophoresis. Analytical Methods, 6, 6066-6072. https://doi.org/10.1039/C4AY00808A

[15] Yang, X.P., Cheng, X.M., Lin, Y.Y., Tan, Z.J., Xie, L.X. and Choi, M.M.F. (2014) Determination of Three Nitroimidazoles in Rabbit Plasma by Two-Step Stacking in Capillary Zone Electrophoresis Featuring Sweeping and Micelle to Solvent Stacking. Journal of Chromatography A, 1325, 227-233. 
https://doi.org/10.1016/j.chroma.2013.11.053

[16] Liu, L., Wan, Q., Xu, X., Duan, S. and Yang, C. (2017) Combination of Micelle Collapse and Field-Amplified Sample Stacking in Capillary Electrophoresis for Determination of Trimethoprim and Sulfamethoxazole in Animal-Originated Foodstuffs. Food Chemistry, 219, 7-12. https://doi.org/10.1016/j.foodchem.2016.09.118

[17] Wan, Q., Liu, Y., Yang, C. and Liu, L. (2017) On-Line Double Focusing of Atenolol and Metoprolol in Human Urine using Capillary Electrophoresis with the Aid of $\beta$-Cyclodextrin. Analytica Chimica Acta, 978, 61-67. https://doi.org/10.1016/j.aca.2017.04.052

[18] Tubaon, R.M., Haddad, P.R. and Quirino, J.P. (2014) High-Sensitivity Analysis of Anionicsulfonamides by Capillary Electrophoresis using a Synergistic Stackingapproach. Journal of Chromatography A, 1349, 129-134.

[19] Rabanes, H.R., Aranas, A.T., Benbow, N.L. and Quirino, J.P. (2012) Synergistic Effect of Field Enhanced Sample Injection on Micelle to Solventstacking in Capillary Electrophoresis. Journal of Chromatography A, 1267, 74-79. https://doi.org/10.1016/j.chroma.2012.08.073

[20] Thang, L.Y., See, H.H. and Quirino, J.P. (2016) Field-Enhanced Sample InjectionMicelleto Solvent Stacking in Nonaqueous Capillary Electrophoresis. Talanta, 161, 165-169. https://doi.org/10.1016/j.talanta.2016.08.054

[21] Azmi, U.Z.M. and Jaafar, J. (2016) Two-Step Stacking of Cationic Analytes by Field Enhanced Sample Injection and Micelle to Solvent Stacking in Capillary Electrophoresis. Proceedings Chemistry, 1, 107-110.

[22] Chong, K.C., Thang, L.Y., Quirino, J.P. and See, H.H. (2017) Monitoring of Vancomycin in Human Plasma via Portable Microchip Electrophoresis with Contactless Conductivity Detector and Multi-Stacking Strategy. Journal of Chromatography $A$, 1485, 142-146. https://doi.org/10.1016/j.chroma.2017.01.012

[23] Dong, Y., Zhang, H., Rahman, Z.U., Zhang, H. and Chen, X. (2012) A New On-Line Concentration Method of Cationic Molecules in Capillary Electrophoresis by a Hyphenated Micelle to Solvent Stacking Coupling with Large Amount Sample Electrokinetic Stacking Injection. Journal of Chromatography $A, 1265,176-180$. https://doi.org/10.1016/j.chroma.2012.09.082

[24] Wuethrich, A. and Quirino, J.P. (2016) Unusual Stacking with Electrokinetic Injection of Cationic Analytes from Micellar Solutions in Capillary Zone Electrophoresis. Analytical and Bioanalytical Chemistry, 408, 8663-8668. https://doi.org/10.1007/s00216-016-9735-1

[25] Quirino, J.P. and Aranas, A.T. (2012) Simultaneous Electrokinetic and Hydrodynamic Injection with On-Line Sample Concentration via Micelle to Solvent Stacking in Micellar Electrokinetic Chromatography. Analytica Chimica Acta, 733, 84-89. https://doi.org/10.1016/j.aca.2012.04.032

[26] Grochocki, W., Markuszewski, M.J. and Quirino, J.P. (2016) Three-Step Stacking by Field-Enhanced Sample Injection, Sweeping, and Micelle to Solvent Stacking in Capillary Electrophoresis: Anionic Analytes. Journal of Chromatography A, 1442, 140 143. https://doi.org/10.1016/j.chroma.2016.03.002

[27] Grochocki, W., Markuszewski, M.J. and Quirino, J.P. (2015) Three-Step Stacking of Cationic Analytes by Field-Enhanced Sample Injection, Sweeping, and Micelle to Solvent Stacking in Capillary Electrophoresis. Journal of Chromatography A, 1424, 111-117. https://doi.org/10.1016/j.chroma.2015.10.089

[28] Yang, X., Zhang, S., Wang, C. and Wang, Z. (2013) Development of Micellar to Solvent Stacking On-Line Preconcentration Technique in Capillary Electrophoresis. 
Chinese Journal of Analytical Chemistry, 41, 1939-1946.

https://doi.org/10.1016/S1872-2040(13)60698-2

[29] Quirino, J.P. and Guidote, A.M. (2011) Two-Step Stacking in Capillary Zone Electrophoresis Featuring Sweeping and Micelle to Solvent Stacking: II. Organic anions. Journal of Chromatography A, 1218, 1004-1010.

https://doi.org/10.1016/j.chroma.2010.12.095

[30] Wang, Q., Qiu, D.H., Han, H.F., Liu, X. and Jiang, S.X. (2012) Two-Step Stacking by Sweeping and Micelle to Solvent Stacking using a Long-Chaincationic Ionic Liquid Surfactant. Journal of Separation Science, 35, 589-595. https://doi.org/10.1002/jssc.201100759

[31] Yang, X., Zhang, S., Wang, J., Wang, C. and Wang, Z. (2014) On-Line Two-Step Stacking in Capillary Zone Electrophoresis for the Preconcentration of Strychnine and Brucine. Analytica Chimica Acta, 814, 63-68.

https://doi.org/10.1016/j.aca.2014.01.027

[32] Breadmore, M.C., Shallan, A.I., Rabanes, H.R., Gstoettenmayr, D., Abdul Keyon, A.S., Gaspar, A., Dawod, M. and Quirino, J.P. (2013) Recent Advances in Enhancing the Sensitivity of Electrophoresis and Electrochromatography in Capillaries and Microchips (2010-2012). Electrophoresis, 34, 29-54.

https://doi.org/10.1002/elps.201200396 


\section{Abbreviations}

$\beta$-CD: $\beta$-Cyclodextrin

BGE: Background Electrolyte

CMC: Critical Micelle Concentration

CTAB: Cetyltrimethylammonium Bromide

CZE: Capillary Zone Electrophoresis

EKI: Electrokinetic Injection

EOF: Electroosmotic Flow

FASI: Field Amplified Sample Injection

FASI-MSS: Field Amplified Sample Injection-Micelle to Solvent Stacking

FASI-Sweeping-MSS: Field Amplified Sample Injection-Sweeping-Micelle to Solvent Stacking

FASS: Field Amplified Sample Stacking

FASS-MSS: Field Amplified Sample Stacking-Micelle to Solvent Stacking

LASEKSI: Large Amount Sample Electrokinetic Stacking Injection

LOD: Limit of Detection

MCE: Microchip Electrophoresis

MEKC: Micellar Electrokinetic Chromatography

MS: Micelle Solution

MSS: Micelle to Solvent Stacking

MSSB: Micelle to Solvent Stacking Boundary

MSS-FASS: Micelle to Solvent Stacking-Field Amplified Sample Stacking

MSS-LASEKSI: Micelle to Solvent Stacking-Large Amount Sample

Electrokinetic Stacking Injection

SDS: Sodium Dodecyl Sulfate

SEF: Sensitivity Enhancement Factor

SEHI: Simultaneous Electrokinetic and Hydrodynamic Injection

Sweeping-MSS: Sweeping-Micelle to Solvent Stacking

TS: Trapping Solution 